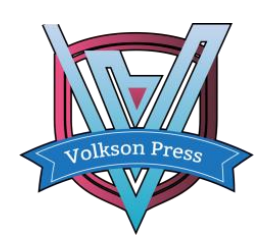

\author{
Contents List available at VOLKSON PRESS \\ DOI : http://doi.org/1010.26480/icie.01.2017.111.117 \\ Journal Homepage: : https://www.intelcomp-design.com/
}

Intelligent Computing and Information Engineering (ICIE )

\title{
TECHNICAL ASPECTS OF RELOCATION OF PRODUCTION AND ASSEMBLY LINES IN AUTOMOTIVE INDUSTRY
}

\author{
Arkadiusz Kowalski ${ }^{*}$, Tomasz Chlebus ${ }^{2}$, Krzysztof Serwatka ${ }^{1}$ \\ ${ }^{1}$ Faculty of Mechanical Engineering, Wrocław University of Science and Technology, 27 Wybrzeże Wyspiańskiego, 50-370 Wrocław, Poland \\ ${ }^{2}$ Faculty of Computer Science and Management, Wrocław University of Science and Technology, 27 Wybrzeże Wyspiańskiego, $50-370$ Wrocław, Poland \\ *Corresponding author email: arkadiusz.kowalski@pwr.edu.pl
}

This is an open access article distributed under the Creative Commons Attribution License, which permits unrestricted use, distribution, and reproduction in any medium, provided the original work is properly cited

\section{ARTICLE DETAILS}

\section{Article History:}

Received 12 May2017

Accepted 12 July 2017

Available online 14 September 2017

Keywords:

Relocation, relocation stages, production line, ramp-up, OEE index.

\section{ABSTRACT}

The paper presents technical aspects of relocation of production and assembly lines. Preparatory stages of relocation, its course, planning and execution, way and process of reaching the assumed mechanical and stability parameters are described. The authors are focused on crucial issues limiting risk: securing supplies to customers by properly large inventory, personnel training and process standardization, transport activities, line assembly after relocation and reaching the target productivity. Effects of relocation on failure and productivity rates are presented. The analysis is based on the data acquired before relocation, in its course and after its completion, as well as during the stages of putting into operation and reaching the required productivity.

\section{INTRODUCTION}

Growing interest in relocation of the whole or a part of production from highly developed countries, being places of origin of numerous companies, to the countries with lower labour costs became visible in early 90 s of 20 th century and could be observed till the first years of 21 st century [1-3].

The reasons for relocation not always must be solely financial issues focused on searching for savings on salaries in the countries with low labour costs. Quite often, the factor that decides relocation of an investment can be access to mineral deposits whose original locations can no longer deliver the required quantity of raw material. The business must remain competitive in the market with still increasing requirements, so it can appear necessary to move it closer to final customers (reducing costs of transport, customs duties and taxes or delivery times) or to search for a larger number of skilled personnel (locating factories in vicinity of academic centres) [4]. Quite often, customers' demand for the manufactured goods exceeds expectations and business plans. This enforces increased productivity that can be only reached by building new production or assembly lines. If no space for new lines is available, it can be necessary to build new shops and relocate the existing lines to new places. In the case of corporations operating several factories, there is a possibility to relocate several lines from the same business unit [5-7].

In many aspects, relocation of a production line can be compared to the initial phase of its starting-up, since the same result is expected: supplying the final customer with the product of required quality, in the required time and quantity. The customer does not want to take the risk related to relocation, so responsibility for the obligations rests with the manufacturer [8]. Relocation brings also additional risks that are absent in a newly created project: the risk of loss or incomprehension of the information, data or guidelines created in the original location. On the road to success, there are many factors and obstacles that could effectively obstruct its reaching, like language barriers, unclear or often unstable political conditions in the new location, complicated supply chains or qualitative changes of final products. To reach a success, i.e. a successful relocation, it is necessary to plan the entire process precisely, to gather a responsible and experienced team whose task would be identifying and considering several factors that could stand in the way to the successful transfer project $[9,10]$.

\section{METHOD OF RELOCATION}

The following stages of the relocation process can be found in the subject literature:

- initiating decisions,

- preparation,

- initial training and education,

- transfer,

- trial production,

- production with moderate output,

- improvement of production,

- $\quad$ production development, continuous improvement and innovation [11].

The authors of this paper have decided to focus on technical side of the relocation process, considering it an important, although of course not the only one, factor of a success of the whole business plan.

\subsection{Preparatory stage}


The stage before relocation actions begin is crucial for the success of the entire undertaking. Plans, arrangements, timeframes and responsibility matrices that will influence the whole project, are created just at this stage. Therefore, it is extremely important that this stage is executed with due diligence for the tiniest details whose improper planning or complete disregarding could lead to a delay of the whole project. In the case of automotive industry, where the JIT principles are implemented, promptness of deliveries is immensely important. Any smallest change of the deadlines could lead to production stoppage at the customer which, in consequence, exposes the supplier to financial penalties.

One of the first and the most important stages is preparation of proper layouts. Before starting any relocation activities, both parties should visit the new production location in order to confirm that it is properly prepared and equipped. Absence of collisions of the relocated production line with the existing installations and machines in the destination factory can be ensured only by highly detailed plans. If no detailed and up-to-date layout of all machines in the line is available, it must be immediately prepared. An important aspect is considering locations of the required utility connections. To that end, utility connection diagrams should be reviewed (or the connections should be drawn in the layout) and next availability and possibility to adapt the connections should be verified. Most often, care should be taken of the following connections:

- water,

- 1-phase and 3-phase electric power,

- chilled water,

- compressed air.

If there are ready utility connections in the destination factory, their parameters should be verified, e.g. air and chilled water pressure, and compared with the requirements imposed in specifications of the machines. During inspection of the connections, their condition should be verified. If the condition is improper or unknown, relevant maintenance technicians should be informed of the necessity to repair or replace the connections, so that commissioning of the line after relocation would not be delayed for this reason. Displacement of the existing connections or installation of new ones together with their inspection should be planned in sufficient advance.

During analysis of the destination location, arrangement of the space should be taken into account, in particular location of pillars and recesses. In old, repeatedly updated plans of the shops that were never used for building a new line, some connections could be incorrectly drawn. Location of each connection, pillar and recess should be confirmed again by measurements and corrections should be plotted in the existing plan.

When machine parts are located close to the existing pillars, it is worth to analyse possibly difficult access to control cabinets and possible disturbances of operation of cooling systems. In the recesses, cabinets for process documentation (specifications, technical documentation, pneumatic and electrical diagrams) or spare parts could be located. When planning new projects, particular attention should be paid to location and possible utilization of existing recesses in order to save valuable space in the shop. The space necessary for required archives and auxiliary consumables like personal protection equipment (protective clothing, gloves, goggles, and helmets), hygienic products or office goods should be estimated.

During site inspections in the shop before relocation, attention should be paid to parts of the connections placed above the floor (cable trays, supporting structures for connections and lighting), often missing in the existing plans of the building, since they could disturb installation of high machines. The observed potential obstacles should be placed in the plan and clearly marked.

Before any disassembly works are started, care should be taken about a sufficient number of high-resolution photographs of all utility connections, their routing and connection to the machines. Utility connections, as well as power and communication couplings should be marked with numbers, so that finding relevant connections would not take too much time after relocation of the line. Connection terminals can be marked with identical numbers or colours, which would speed-up their new connection after relocation. When taking pictures of the connections, it is worth to take additional pictures of all machines, arrangement of tools, view of panels etc. That would ease restoring the line to the condition before relocation.

Before starting the disassembly and transport works, a list of all recording-controlling instruments, auxiliary and peripheral devices should be made, including their identical physical designations. For the equipment that requires periodic validation, inspection records should be available. This would make it possible to start manufacture together with peripheral processes with no necessity to perform initializing validations of the recording-controlling instruments. The so prepared list would also facilitate inventory control of machinery and tooling after shipment. For the instruments with approaching validation dates, it would be worth to inspect them and prolong their admission to use even before relocation.

In the automotive sector, special care should be taken of availability and identification of all reference parts, exemplary components and finished products used for inspections resulting from the control plan in order to avoid problems during first customer's audits. When different standards concerning inventory marking of the tools requiring periodic inspection exist in both locations, transition matrices are created, containing present and new names. Information about the matrix must be placed in the inspection plan. As a target, old designations should be converted to new ones to avoid incompatibilities during audits.

An important aspect is comparison of the requirements related to industrial safety, ergonomics or machinery directives [12]. Quite often, especially in the case of intercontinental transfers, many differences exist in the requirements, directly resulting in a necessity to introduce changes and adaptations in settings and structures of the machines. A particular attention should be paid to safety issues. Changes can be related to dimensions of safety zones, settings of light curtains, possible pressure forces of movable guards against operators' hands etc. In this case, it is worth to collect present requirements in the old location and consult them with the factory labour safety inspector to be aware of the necessary changes.

Before starting disassembly, devices requiring calibration according to ISO/TS should be listed:

- sensors,

- measuring instruments,

- converters.

Influence of changed atmospheric conditions (temperature and humidity) should be analysed in detail, as well as lighting levels in both locations. Even small changes of these factors can significantly affect manufacturing processes, as a result of e.g. properties of silicones or lubricants used in the process, changing with ambient temperature or humidity. Even apparently insignificant differences can significantly change e.g. dosing pressure and thus result in exceeding the tolerances controlled by measuring systems. If the tolerances are precisely defined in internal standards and process specifications, such a change can make it necessary to modify parameters and tolerances urgently, which often requires additional mechanical or functional testing.

\subsection{Securing supplies to customers}

The extremely important aspect to be considered is gathering a significant inventory of finished products before starting relocation of the production line [13]. The inventory can appear unnecessary, if the relocation project is finished in time. However, it can appear necessary if any unpredictable event occurs, resulting in a delay. The time required for ramp-up of the line after relocation should be planned deliberately and with no excessive optimism. The rampup process itself is relatively well known and described [14-16]. 
In the automotive industry, reaching the productivity level of 80\% OEE takes usually over a dozen weeks but, with regard to possible difficulties during production start-up, duration ca. two times longer should be considered.

It is worth to prepare an emergency plan, e.g. significant production increase on another line manufacturing identical product or adaptation of a similar line to manufacture of the transferred product, e.g. in the case of a transport accident of the machines to be assembled or other random incidents. A possibility of engaging or displacing additional employees and starting additional shifts in other lines should be planned, which, together with increased number of operators, would secure supplies to customers for a period of even several months. If a part of the machinery is lost (theft, accident or transport damage), this would secure the time for its renewed building. It should be also remembered about appropriate insurance of the shipments.

\subsection{Personnel training and process standardization}

Training of the personnel who are to take over production management after relocation should be started even before stopping series production in the original location. A very good idea is to prepare at least one production shift composed of the operators designed for series production in new location even before relocation. It is practised to join newly employed operators with experienced staff in the original location and to let them work together for several months, which facilitates gaining good habits, unofficial knowledge and basic skills of solving problems.

It is worth to implement similar actions in the field of engineering, as well as of widely understood maintenance services. An investment in „on-the-job" training will be refunded soon by increased productivity and reduced down-times thanks to faster identification and recovery of failures by this way trained services [17].

An immensely important thing is elaboration of a good, multilevel personnel training plan. Properly oriented trainings will make possible quick acquiring knowledge from adequate employees in the original location. The plans must consider availability of relevant experts. During elaboration of the plans, future responsibilities of the newly engaged and trained employees should be taken into account, so that they would not be overloaded with useless knowledge and could be focused on their job. For this purpose, care should be taken of building a proper matrix informing of taking-over specific duties by specific persons; preferably by names (i.e. a specific person in the new location takes duties from a given person in the previous location). This will provide transparency when a contact is necessary to obtain possible support on technical issues.

A training matrix specifies the persons responsible for execution of each training, suggested dates of the trainings and the persons who should participate in individual trainings adapted to the job position profile [11].

A typical training matrix includes the following information:

A - training subject,

B - new staff members participating in the training,

C - training tutors,

$\mathrm{D}$ - date and status of the training,

E - assignment of staff members to individual trainings,

$\mathrm{F}$ - planned durations of the training.

One of the points of a matrix for general trainings is shown in Figure 1.

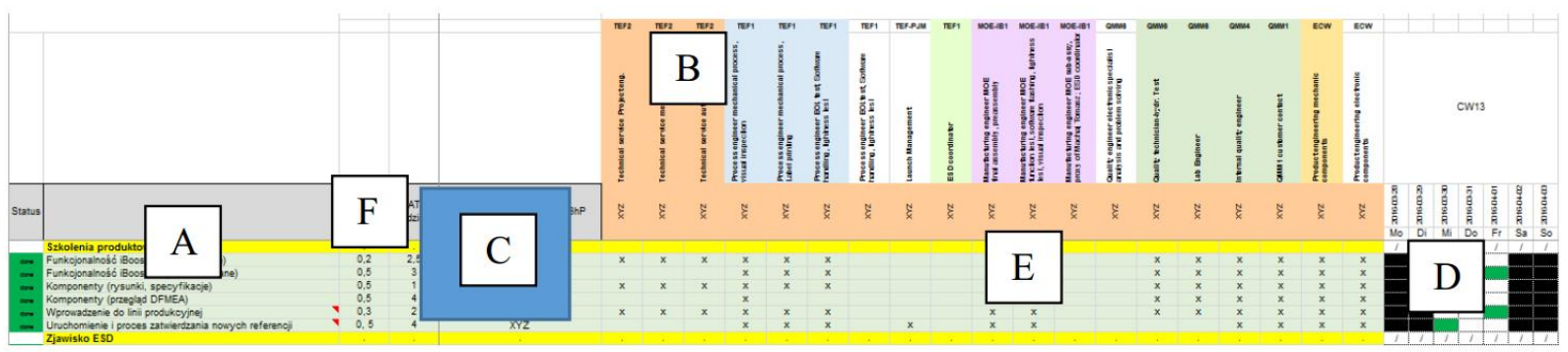

Figure 1: Key areas of a general training matrix

It is worth to take care of appropriate agreements concerning temporary taking-over the duties by new personnel, as well as initial support from the parent factory (or original production location) on technical questions during building competences in the new staff. Otherwise, disagreements and complications about settling costs of the specialized support can appear.

During process trainings received by production technicians who will take over the duties related to manufacture after relocation, it is worth to accomplish translations of any available process documentation (internally executed by the engineering staff). This will make it possible to reduce the labour to be performed after relocation and also to familiarize with procedures, processes and existing documents.

\subsection{Activities during transport}

Before transport processes begin, care should be taken of proper training of the companies and employees executing shipments. A particular attention should be paid to the guidelines concerning maximum pressures that can be exerted on the machines or their parts, e.g. during lifting (pressure on the machine bottom). The guidelines must be written in details and transferred to the persons and companies responsible for transport activities. Before loading, proper safeguarding of the machines against sliding from the pallets must be inspected, as well as safeguarding or disassembling and securing in other places any movable components situated inside the machines.

After fragments of the line are delivered by successive shipments, machines and devices must be checked for damages and completeness. Lists of peripheral equipment and machine parts would be useful. Before loading, information about contents of individual shipments should be added to the lists, which can be helpful if some small parts or small devices are lost.

\subsection{Assembly of the line after relocation}

When the engaged companies or services execute connection and assembly works, it is worth to spend some time on building a detailed process validation plan of the line before it is started-up to series production. It is worth to collect all the available process documentation, specifications, standards and customers' requirements and then determine all validation actions for each of the machines and processes. Matrices for supervising results of process capacity (as well as large-size check lists) are placed in a visible place on the production line for the purpose of daily updating the validation status and accepting individual machines for series production. 
After integration of the line is completed, it is worth to plan successive trial production series to verify correctness of integration, functioning of control and monitoring systems, as well as initial performance indices. Each of the machines should be checked for correct operation of known functions and quality of panel translations. During trial runs, it is worth to engage the engineering staff for measuring cycle times and recording any found problems and incompatibilities. Any observed complications should be acquired and persons responsible for their solving should be assigned, e.g. during daily (or taking place several times a day) meetings summarizing integration of the line. The time when the companies executing integration of the line and technicians from the parent factory are available, should be used for solving as many problems as possible, which would make it possible to safe the time for solving them during series production, when the newly trained staff can face many problems related to unavoidable gaps in their knowledge.

Progress of the works should be currently monitored and summarized during common meetings. Timeliness of the activities should be continuously compared with the assumed time axis to minimize and early detect possibly appearing delays.

\subsection{Process of reaching destination productivity}

Effective maintenance management is essential for companies where ensuring continuous and fault-free operation is required [18]. In order to assess effectiveness of all the accomplished actions, the obtained performance parameters of the line should be currently monitored. Any early observed and recognised alarming trends in specific performance parameters should induce to define and effectively implement corrective actions in order to prevent failures to meet delivery dates and to avoid delays with respect to the project timing. Figure 2 shows mean increase of the overall equipment effectiveness (OEE) index. The diagram should be treated as a representative effectiveness increase possible to be reached in relocation projects of automated and semiautomated lines used for assembly processes.

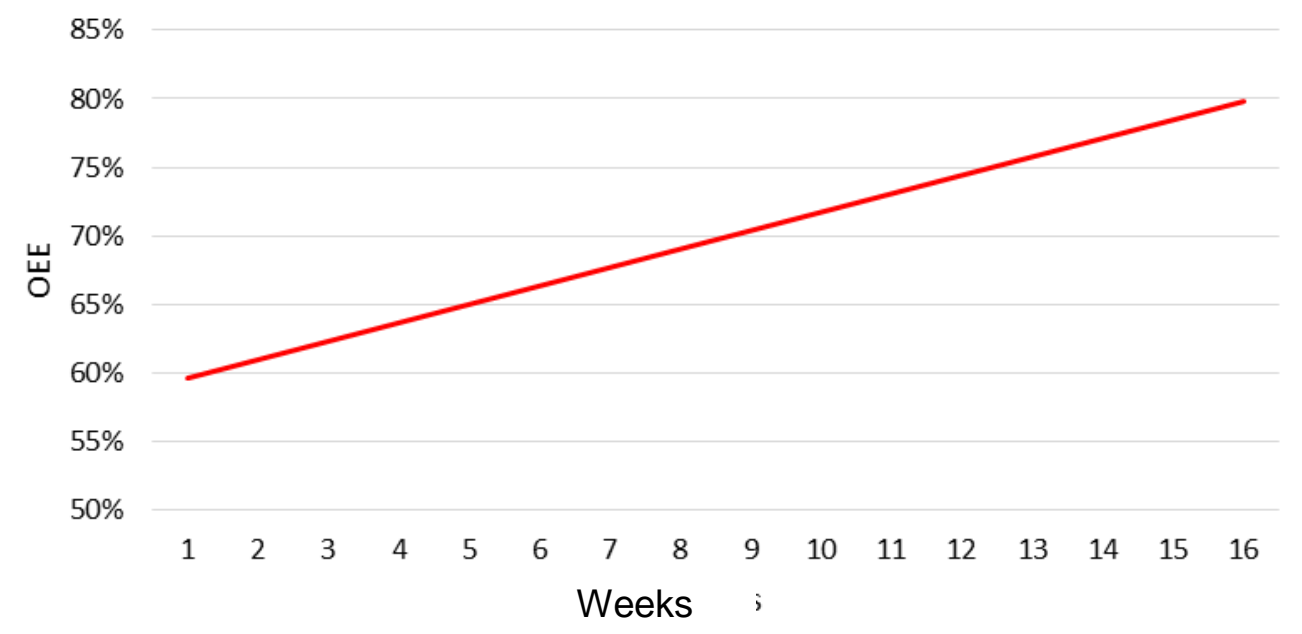

Figure 2: Mean weekly increase of overall equipment effectiveness after relocation

An increase of OEE by ca. 20 percentage points should be expected during four months after relocation of the production line. A condition for obtaining such results is conducting secondary projects of stabilisation and/or reduction of cycle times, shutdowns, first-pass yield (FPY) or percentage of rejects. In addition, initial level of the equipment effectiveness (at that productivity improvement began after relocation) should be considered, as well as kind of the assembly line and industry [19]. Increase of the OEE level is affected also by human factors (especially in the case of manual and semi-automatic lines), like education and process experience levels of production workers. This factor is difficult to be quantified, but it cannot be ignored, and efforts should be made to enable the machine operators (production operators, setters and servicemen) to develop their knowledge. One of the indices on that ground progress in education of servicemen can be evaluated is mean time to repair (MTTR) counted from the moment when a failure is reported to the moment when it is repaired. An additional indicator showing increase of effectiveness of preventive maintenance, and thus decrease of failure frequency of the machines, is mean accumulated down-time (MADT). A trend of MTTR changes during the first 4 months is shown in Figure 3 and that of mean monthly down-time is shown in Figure 4. Most often, MADT decreases ca. 10\% after first 4 months of the line operation after relocation. After that period, MTTR drops ca. 20\%. Values of these indices indirectly indicate increased productivity and general effectiveness of the line.

One of key actions leading to higher productivity of the line after relocation is conducting projects aimed at increasing the FPY factor. A model growth of FPY during first 4 months after relocation is shown in Figure 5.

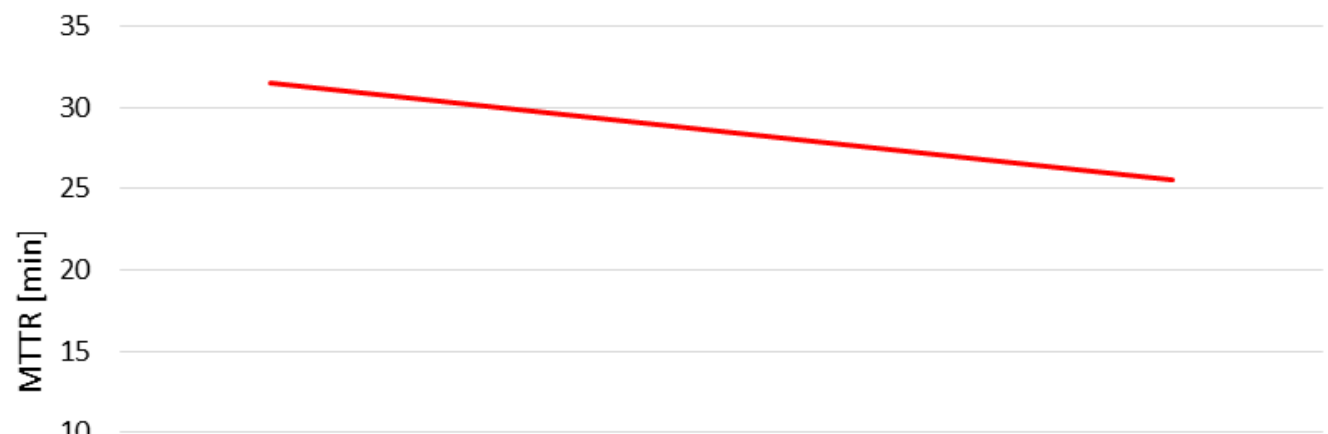

10 
Figure 3: Mean time to repair during first 4 months after relocation

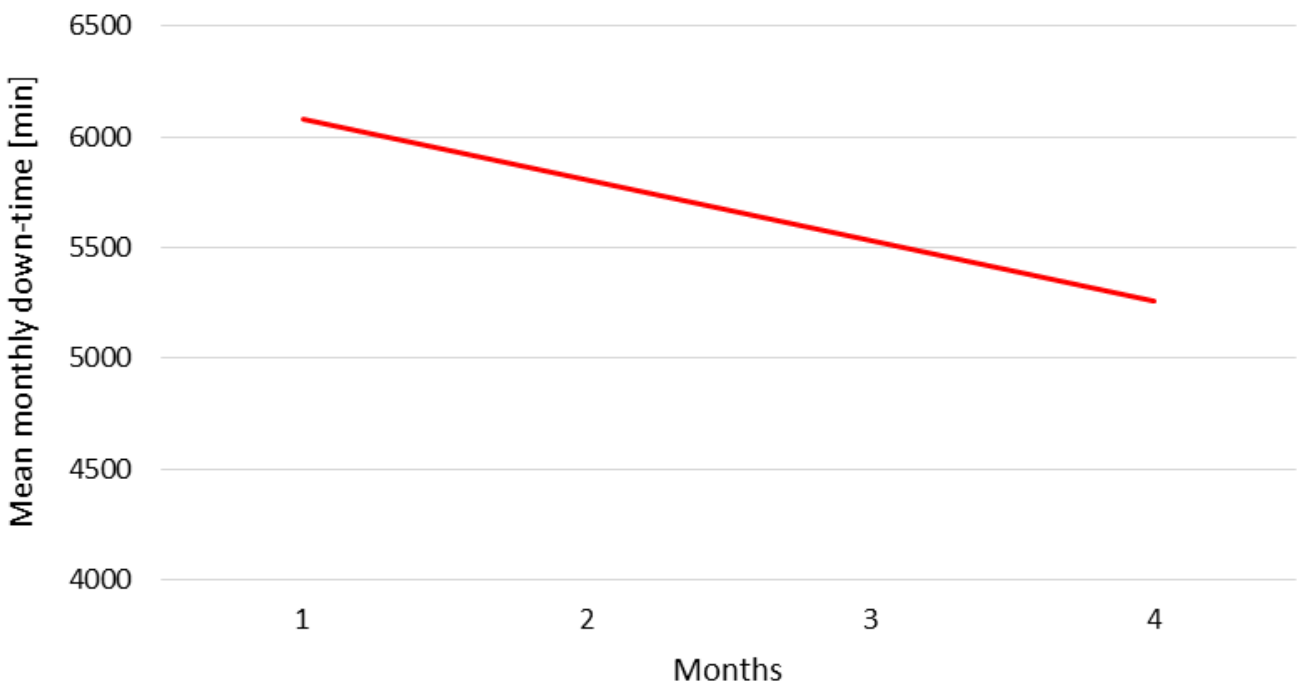

Figure 4: Mean monthly down-time during first 4 months after relocation $100,0 \%$

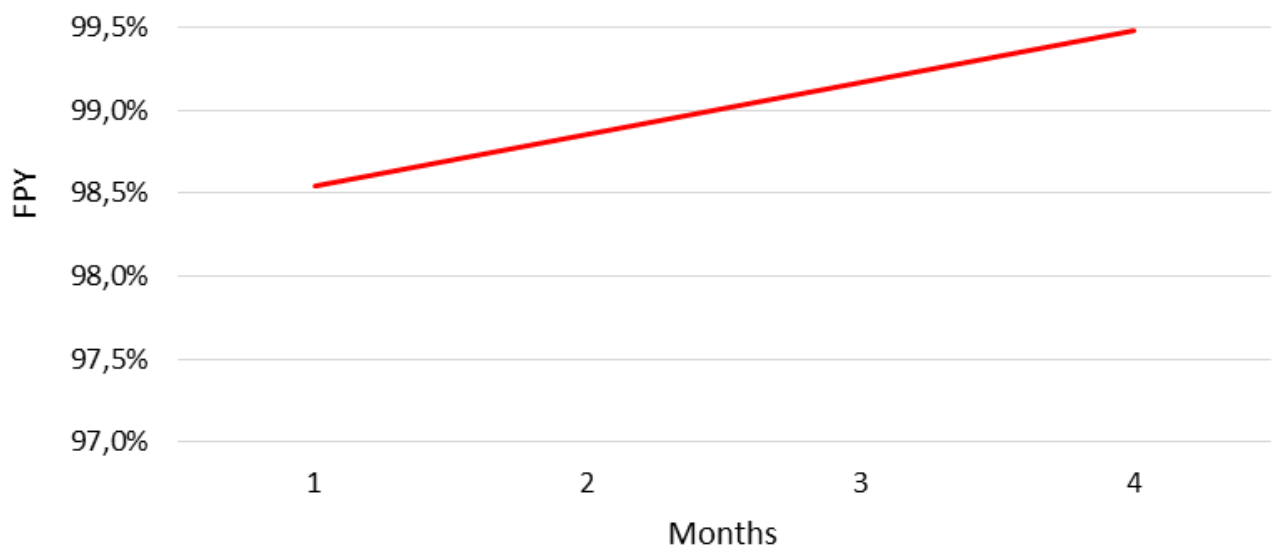

Figure 5: Mean monthly first-pass yield during first 4 months after relocation

It is possible to reach average increase of FPY value at 0.25 percentage point per month, which plays a significant role in OEE increase presented in Figure 2. In relocation projects, attention is normally focused on three work stations/stands showing the lowest FPY level that is increased with use of procedural problem-solving methods. The introduced actions influence at the same time a percentage decrease of incompatible pieces by a reduction of errors in assembly processes. Application of additional actions to reduce rejects on work-stations showing their highest level makes it also possible to reduce total cost of rejects, presented in Figure 6 by percentage of incompatible pieces in production.

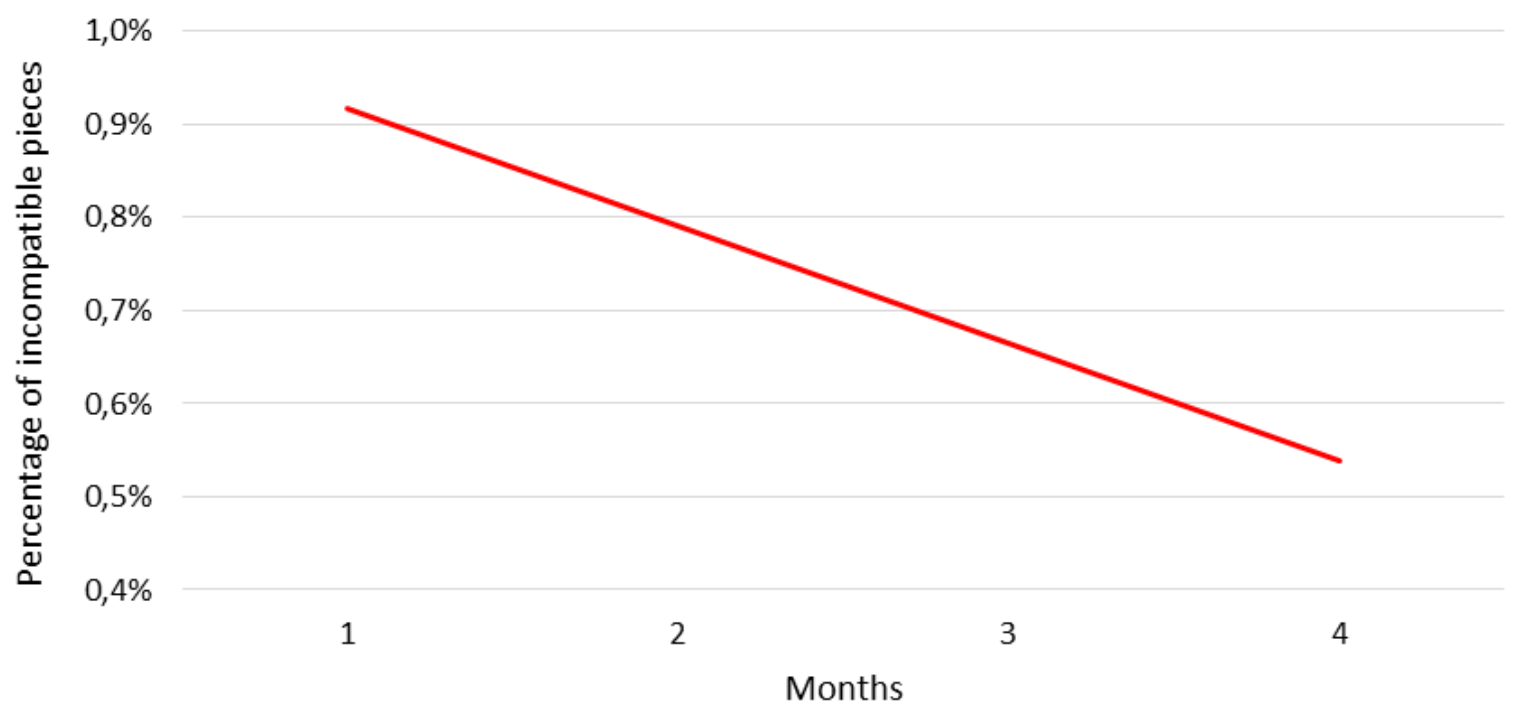

Figure 6: Percentage of incompatible pieces during first 4 months after relocation 
Mean monthly decrease of percentage of incompatible pieces at the level of 0.1 percentage point was observed, which made it possible to reduce total rejects by ca. $40 \%$ during the first 4 months after relocation of production. In the case of the considered company and type of process (assembly), these values are repeated in many projects; however, they should be treated as approximate, dependent on industry and kind of manufacturing process.

\section{CONCLUSIONS}

Even a tight and experienced team is unable to realise a good and successfully completed project of production relocation without proper planning. The synthetic list of actions at individual stages of relocation, shown in Table 1, is to facilitate this task.

Undoubtedly, from the viewpoint of the possibility to secure a suitable number of pieces of finished product for the customer, the most important parameter is OEE. Therefore, it is most often selected as a key parameter at efficiency assessment of the relocation project and of implementing the line to series production. For relocated production lines, OEE data from the periods before and after relocation are important. In addition, information about the parameters like down-times, production capacities and reject levels are also important.

The key objective of relocation of a production line is that the line after relocation is able to supply more finished products than it was in its original location, with respectively lower labour cost of operators and auxiliary services. In case sufficient OEE levels were not reached, it would be necessary to start additional production shifts on off-work days (Saturdays, Sundays and public holidays), which is in conflict with the idea to reduce labour costs.

Successful relocation of a line is confirmed by values of selected production indices, but the highest risk of the project is a failure to secure continuity of supplies to customers and a visible change of product quality, which could affect final evaluation of the company as a supplier and result in reduced customers' orders or even their moving to competition.

Table 1: Technical details of relocation of production and assembly lines

\begin{tabular}{|c|c|}
\hline Stage & Task \\
\hline \multirow{17}{*}{ 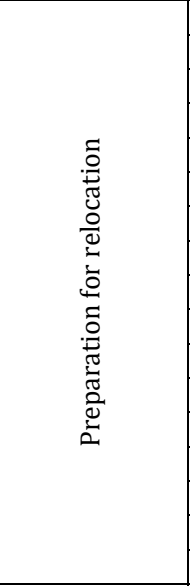 } & Inspection visits - preparation of both locations to the relocation project \\
\hline & Preparing a detailed and up-to-date plan of arrangement plan of relocated machines \\
\hline & Considering location of utility connections \\
\hline & Verification of parameters of utilities \\
\hline & Verification of condition of utility connections \\
\hline & Considering locations of pillars and recesses \\
\hline & Considering constructional elements above the floor \\
\hline & Determining the space required for documentation and auxiliary materials \\
\hline & Taking pictures of utility connections and marking the connections \\
\hline & Preparing a list of control and measurement instruments, auxiliary and peripheral devices \\
\hline & Putting physical marks on measuring instruments, auxiliary and peripheral devices \\
\hline & Verification of availability and identification of reference parts \\
\hline & Building a transition matrix of markings of the devices requiring periodic calibration \\
\hline & Comparing requirements related to occupational safety, ergonomics, directives etc. \\
\hline & Preparing a list of the devices requiring periodic calibration \\
\hline & Analysis of influence of changed atmospheric conditions \\
\hline & Analysis of possibilities of transferring spare parts \\
\hline \multirow{3}{*}{ 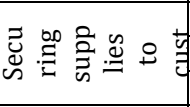 } & Estimation and building inventories \\
\hline & Planning the time required for ramp-up relocation \\
\hline & Elaborating an emergency plan \\
\hline \multirow{4}{*}{ 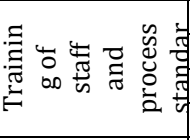 } & Plan of personnel training \\
\hline & Agreements related to support from the parent factory in the first phase of production \\
\hline & Completing and translation of available process documentation \\
\hline & Translation of machinery documentation \\
\hline \multirow{3}{*}{ 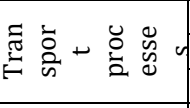 } & Training of employees of transport companies \\
\hline & Securing proper insurance of machines during shipment \\
\hline & Inspection of machinery condition after delivery \\
\hline \multirow{3}{*}{ 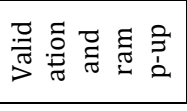 } & Preparing a validation plan of the line \\
\hline & Carrying-out trial production runs \\
\hline & Verification of correctness of translations of panels and interfaces \\
\hline
\end{tabular}

The described experiments and variability of key production parameters were taken by the authors from three successful relocation projects and were acquired in order to compare rates of productivity increase with assumptions of business plans. The attainable improvement rate of selected production indices, determined on the grounds of acquired and here presented data, should make a comparative basis for planning and determining real productivity objectives for new relocation projects.

\section{REFERENCES}

[1] Kinkel, S., Zanker, C. 2013. New patterns of German production relocation and back shoring activities after the global economic crisis, Paper presentato all'EURopean Operations Management Association (EurOMA), Dublino, Irlanda, 7-12.

[2] Vestring, T., Rouse, T., Reinert, U., Varma, S. 2005. Making the move to low cost countries. Supply Chain Strategy, 1 (2), 1.

[3] Kumar, N., Andersson, D., Rehme, J. 2010. Logistics of low cost country sourcing. International Journal of Logistics Research and Applications, 13 (2), $143-160$.

[4] Kłosowski, G., Gola, A., Świć, A. 2016. Application of Fuzzy Logic in Assigning Workers to? Production Tasks, in Distributed Computing and Artificial Intelligence, 13th International Conference, vol. 474, S. Omatu, A. Semalat, G. Bocewicz, P. Sitek, I. E. Nielsen, J. A. García, and J. Bajo, Eds. Cham: Springer International Publishing, 2016, pp. 505-513, DOI: 10.1007/978-3-319-40162-1_54.

[5] Kinkel, S. 2015. Trends and patterns of R\&D relocation and co-location, in ISPIM Conference Proceedings, 1.

[6] Brown, D. 2017. Factors for Relocating a Business. [Online]. Available: http://smallbusiness.chron.com/factors-relocating-business-

21155.html.[Accessed:19-Jun-201]. 
[7] Stentoft, J., Olhager, J., Heikkilä, J., Thoms, L. 2016. Manufacturing backshoring: a systematic literature review. Operations Management Research, 9 (34), 53-61.

[8] Kłosowski, G., Gola, A. 2016. Risk-based estimation of manufacturing order costs with artificial intelligence, presented at the Federated Conference on Computer Science and Information Systems (FedCSIS), Gdańsk, 729-732, DOI: 10.15439/2016F323.

[9] Malm, A., Fredriksson, A., Rudlund, M., Björkman, M., Johansen, K. 2012. Production Start-up Phase-A Comparison between New Product Development and Production Relocation, in 5th Swedish Production Symposium (SPS 2012), 6-8 November 2012, Linköping, Sweden.

[10] Aaboen, L., Fredriksson, A. 2016. The relationship development aspect of production transfer. Journal of Purchasing and Supply Management, 22 (1), 53-65.

[11] Riis, J. O., Waehrens, B. V., Madsen, E. S. 2009. The Knowledge Dimension of Production Transfer, in IFIP International Conference on Advances in Production Management Systems, 441-448.

[12] Jasiulewicz-Kaczmarek, M., Saniuk, A. 2015. Human Factor in Sustainable Manufacturing, in Universal Access in Human-Computer Interaction. Access to the Human Environment and Culture, vol. 9178, M. Antona and C. Stephanidis, Eds. Cham: Springer International Publishing, 444-455. DOI: 10.1007/9783-319-20687-5_43.

[13] Lenart, B., Grzybowska, K., and Cimer, M. 2012. Adaptive inventory control in production systems, Hybrid artificial intelligent systems, 7th International Conference, HAIS 2012, Proceedings. Part II / E. Corchado et al. (eds.)., Springer, pp. 222-228. DOI: 10.1007/978-3-642-28931-6_21

[14] Haller, M., Peikert, A., Thoma, J. 2003. Cycle time management during production ramp-up. Robotics and Computer-Integrated Manufacturing, 19 (1), 183-188.

[15] Terwiesch, C., Bohn, R. E. 2001. Learning and process improvement during production ramp-up. International journal of production economics, 70 (1), 1-19.

[16] Bohn, R. E., Terwiesch, C. 1999. The economics of yield-driven processes. Journal of Operations Management, 18 (1), 41-59.

[17] Mikołajczak, P., Napiórkowski, J. 2016. Analyzing the reliability of working parts operating in abrasive soil pulp taking into consideration confounding factors. Maintenance and Reliability, 18 (4), 544-551.

[18] Rosienkiewicz, M., Chlebus, E., Detyna, J. 2017. A hybrid spares demand forecasting method dedicated to mining industry. Applied Mathematical Modelling, 49, 87-107.

[19] Grzybowska, K., Gajdzik, B. 2012. Optimisation of equipment setup processes in enterprises. Journal Metalurgija, 51 (4), 563-566. DOI: 65.01:669.013.003:658.5:658.8=111. 